\title{
A Systematic Review of Anterior Cruciate Ligament Reconstructions with Hamstring Autograft in Patients Over 50 Years of Age
}

\author{
Gautam Yagnik*, Michael Mashura, Anshul Saxena, John Uribe, Luis Vargas \\ Miami Orthopedics \& Sports Medicine Institute (MOSMI), Baptist Health South Florida, USA
}

*Corresponding author: Gautam Yagnik, Miami Orthopedics \& Sports Medicine Institute (MOSMI), Baptist Health South Florida, Coral Gables, FL, USA 33146, USA

\begin{abstract}
Background: While ACL injuries in older patients have historically been treated non-surgically, several recent studies have demonstrated excellent clinical outcomes with ACL reconstruction in patients over 50 years of age. Despite these outcomes, the ideal graft choice in this age group has yet to be defined.

Objective: The purpose of this study was to systematically review the literature and analyze the clinical outcomes, failure rates and complication rates in patients over the age of 50 who have undergone ACL reconstruction using a hamstring autograft.

Methods: A systematic review of the literature was performed according to the PRISMA guidelines and included English studies from January 2000 to 2020. Studies that reported on outcomes of patients over 50 years of age undergoing ACL reconstruction with a hamstring autograft were included. Studies with other graft types, patients under 50 and expert opinions were excluded. Data consisted of patient demographics, physical exam findings, functional outcome scores, failure rates and complications.

Results: 6 studies met the inclusion criteria and included 167 patients with a mean age of 54.8 (50-71). Mean follow up was 41.4 (12-72) months. All studies demonstrated a significant improvement in functional outcomes at final follow up, including IKDC, Lysholm, and Tegner scores. Very few complications and no clinical failures or revisions were reported in this cohort.

Conclusions: The results of this systematic review support hamstring autograft as a viable graft option for ACLR in patients over 50 with excellent functional outcomes, high patient satisfaction, low failure rates and minimal donor site morbidity.
\end{abstract}

Keywords: ACL: Anterior Cruciate Ligament; Reconstruction; Hamstring Autograft; Advanced Age

\section{Introduction}

Anterior cruciate ligament (ACL) rupture is one of the most common injuries seen in orthopedic sports medicine with over 129,000 occurring every year [1]. Until relatively recently, operative treatment has focused mostly on younger active athletes while older individuals were treated conservatively. Ciccotti et al. have reported an $83 \%$ satisfaction rate at final follow-up for older patients with an ACL tear treated conservatively [2]. Despite the high patient satisfaction rate, the authors noted persistent instability on exam in $97 \%$ of the patients and a reinjury rate of close to $40 \%$, calling into question the benefit of conservative treatment in this age group. With an ever-increasing number of active individuals and increasing life expectancy, more and more patients are participating in high risk activities for ACL injury well into the later years of life. As a result, there has been an increasing number of studies evaluating the clinical outcomes of ACL reconstruction in older patients [3-16]. While 40 years of age has traditionally been the cut off for older patients, several published case reports have documented satisfactory clinical outcomes in patients in their 70 s and 80 s [11-15]. Because of this growing evidence, many have advocated for ACL reconstruction (ACLR) regardless of the age of the patient in the absence of advanced degenerative changes in the knee. Despite the positive outcomes of ACL reconstruction in older patients, the ideal graft choice in patients over the age of 50 remains 
controversial. While allograft is commonly utilized, several studies have advocated for the use of hamstring autograft in this population demonstrating excellent clinical outcomes and minimal donor site morbidity. The purpose of this study was to systematically review the literature and analyze the clinical outcomes in patients over the age of 50 who have undergone ACL reconstruction using a hamstring autograft. The secondary purpose was to characterize the overall failure and complication rate.

\section{Methods}

A systematic review of the literature was performed per the PRISMA (Preferred Reporting Items for Systematic Reviews and Meta-Analyses) guidelines.

\section{Search Strategy and Criteria}

A literature search was conducted in the PubMed, Ovid, EMBASE, and Medline databases for studies in the English language between January 2000 and March 2020. Keywords used to identify relevant articles included "anterior cruciate ligament" OR "ACL" AND "50" OR "aged" OR "aging” OR "older patient". Filters activated included: clinical trial, comparative study, controlled clinical trial, meta-analysis, multicenter study, observational study, randomized controlled trial, review, systematic reviews, validation studies, humans, and English. The focus was to study the various outcomes reported after ACLR among patients who are 50 years or older and had a hamstring autograft. Studies included prospective cohort studies, retrospective studies, and case series. A cohort of patients over the age of 50 years undergoing ACL reconstruction with a hamstring autograft was the primary inclusion criteria. Studies that did not have all patients treated with hamstring

Mean $_{\text {change }}=$ Mean $_{\text {postop }}-$ Mean $_{\text {preop }}$

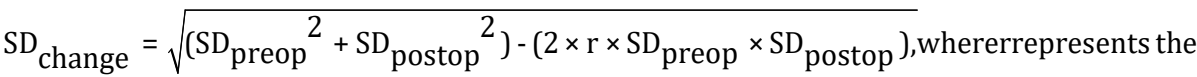

correlation coefficient.r $=0.4$ was used as a conservative estimate in this study.

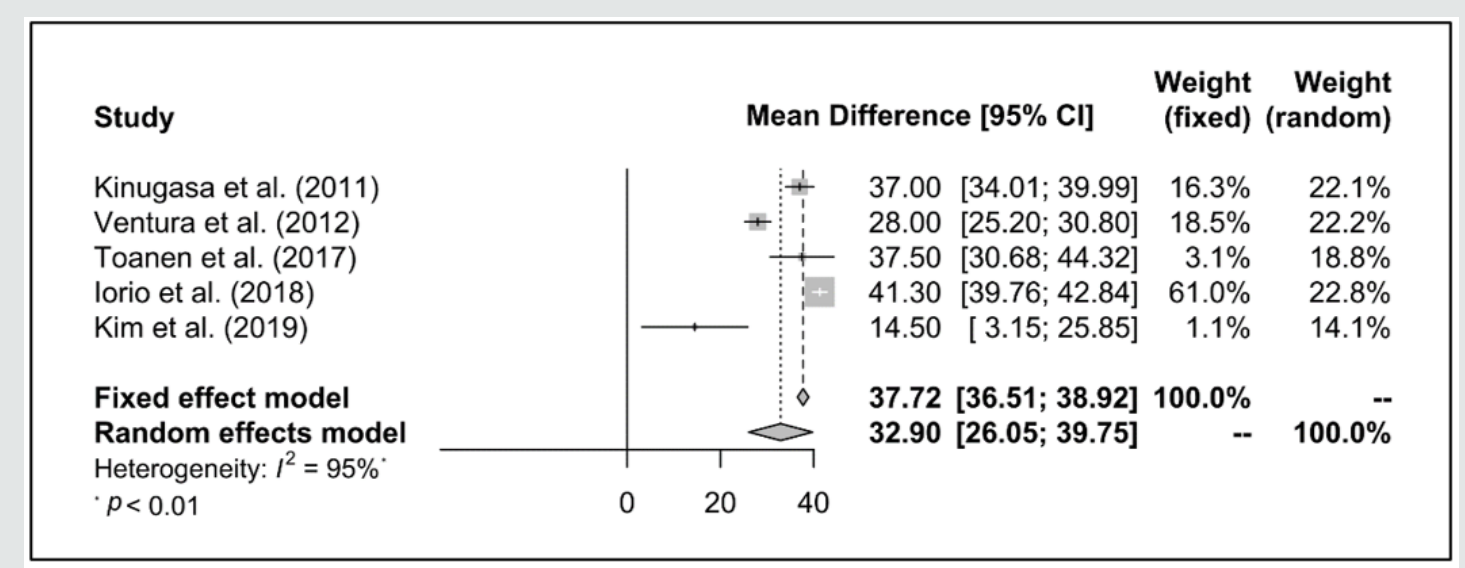

Figure 1: Forest plot for Difference in mean pre- and post-operative Lysholm score. autograft, expert opinions, nonclinical studies, clinical studies that did not include a cohort over 50 years of age, clinical studies that were primarily centered on arthroplasty and studies in which the primary pathology did not involve the ACL were excluded from the analysis.

\section{Extraction of Data and Synthesis}

The primary outcomes were clinical and functional results such as Lysholm score and International Knee Documentation Committee (IKDC) score. These scores were extracted independently (M.M and G.Y) and presented as the mean with range of values listed in parentheses. Both pre-operative and post-operative scores were evaluated when available. To evaluate patient's activity level, the Tegner activity score was used where 0 represented disability because of knee problems, and 10 represented the highest score corresponding to national and international elite competitive sports. Failure rate was also extracted which corresponded to a need for surgical revision due to recurrent ACL tear. The Lachman test and pivot-shift test were also assessed. An exam of 0-1 was listed as negative and 2-3 were listed as positive for both tests. Patient satisfaction information was also evaluated when listed.

\section{Statistical Analysis}

The meta-analyses were carried out using STATA software version 14 (Stata Corp, College Station, TX) and R software version 3.6.3. Heterogeneity was quantified by I2 statistic. A random-effect (Figure 1 and 2). Differences in change of mean and standard deviation were calculated using: 


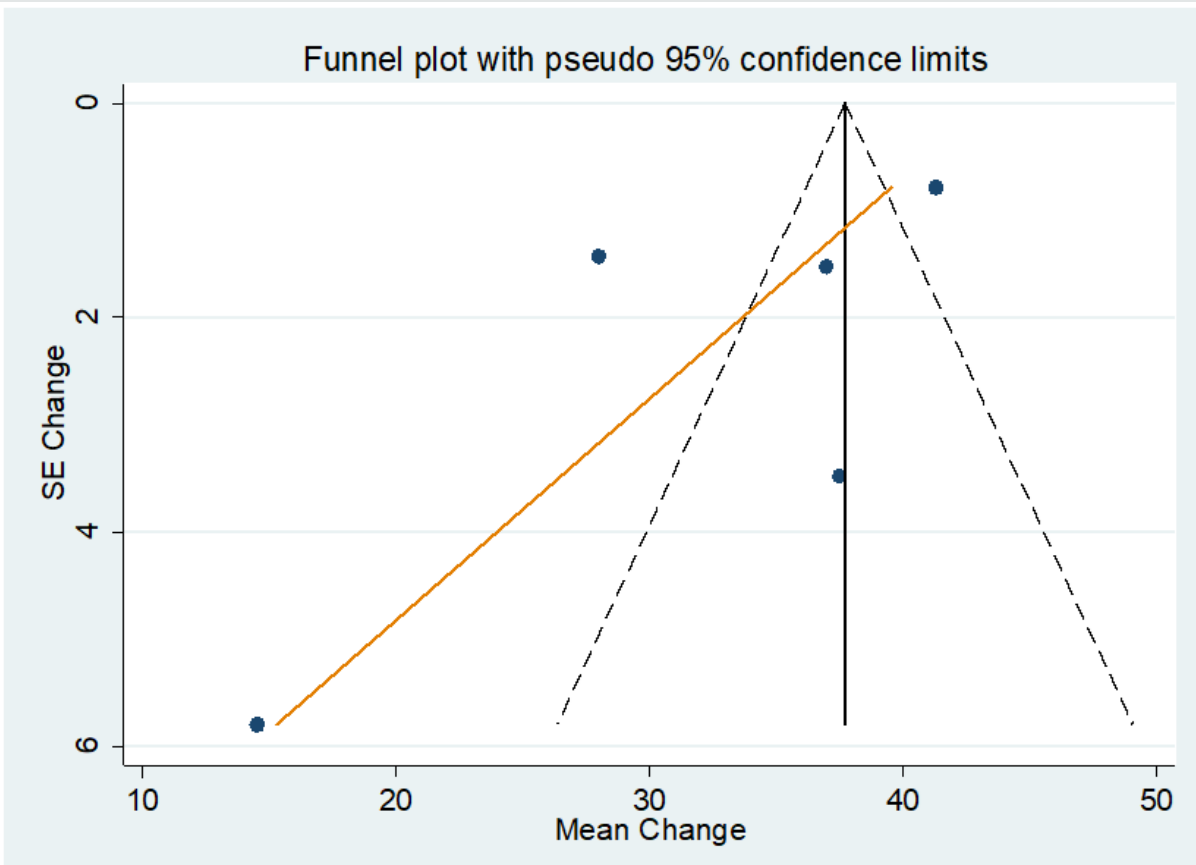

Figure 2: Funnel plot for publication bias.

\section{Results}

\section{Study Selection}

After application of our inclusion and exclusion criteria using the PRISMA guidelines, our initial search yielded 5,248 articles for consideration on PubMed and 10,020 on Ovid databases (Table 1).
The selected articles were then filtered by abstract for relevance, and 34 studies were identified. After a thorough full-text review, 17 articles were identified that contained only patients aged over 50 years but, these were further filtered to 6 studies, which only contained patients treated with a hamstring autograft.

Table 1: PRISMA (Preferred Reporting Items for Systematic Reviews and Meta-Analyses) flow diagram.
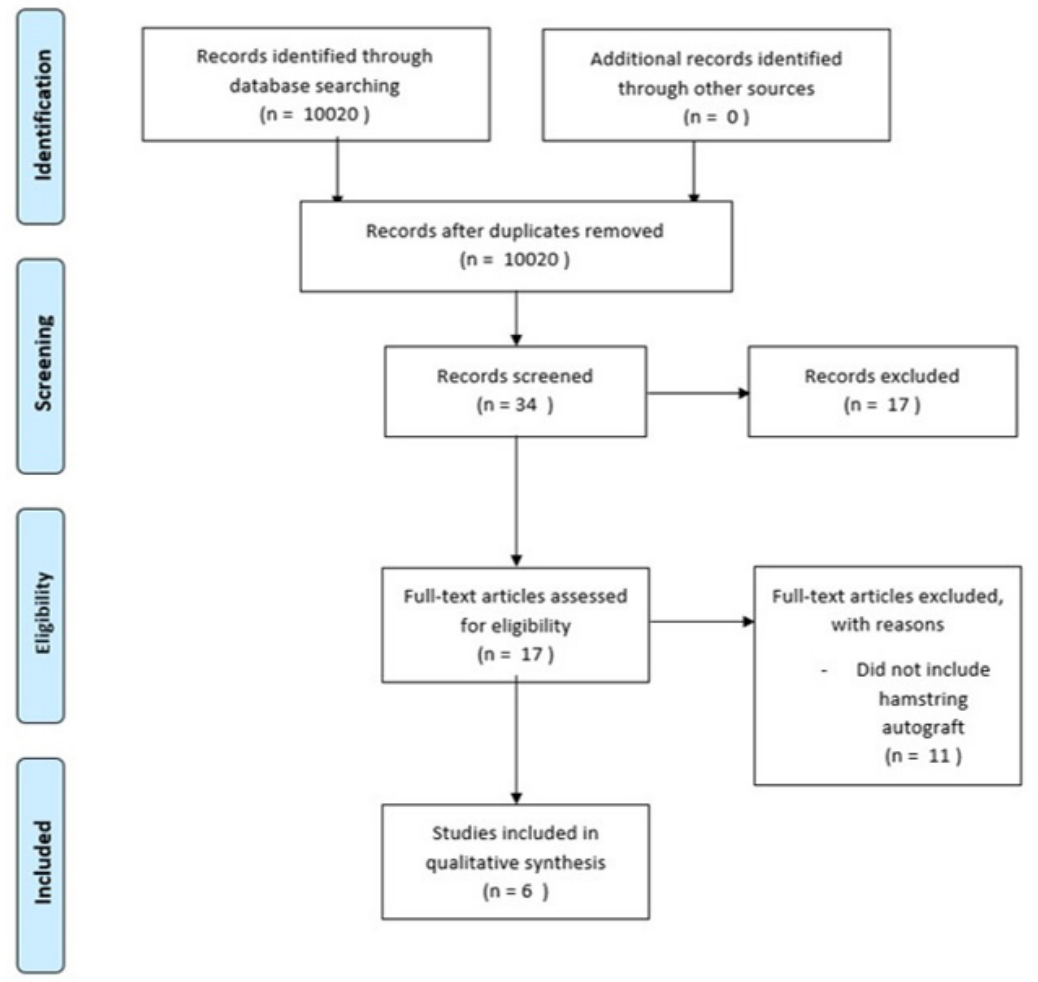

Citation: Gautam Yagnik, Michael Mashura, Anshul Saxena, John Uribe, Luis Vargas. A Systematic Review of Anterior Cruciate Ligament Reconstructions with Hamstring Autograft in Patients Over 50 Years of Age. Orthop \& Spo Med Op Acc J 4(4)- 2020. OSMOAJ.MS.ID.000193. DOI: $10.32474 /$ OSMOAJ.2020.04.000193. 


\section{Study Characteristics and Quality}

The six studies identified were English language articles with 3 retrospective case studies, 2 retrospective cohort study, and 1 prospective cohort series. These studies aggregated to 167 knees with 167 hamstring autograft ACLR.

\section{Patient Demographics}

The minimum and maximum reported mean age was 50 and 71 years respectively (Table 2). The pooled mean age (95\% CI) was $54.29(52.26,56.32)$ years. Mean time to surgery ranged from minimum 1 and maximum 158 months. Mean follow-up time ranged between 12 and 72 months. The pooled follow-up time was $38.82(12.99,64.66)$ months.

\section{Physical Exam Findings}

Post-operative Lachman exam and pivot shift were reported in 5 studies for a total of 91 patients [8-16] (Table 3). The Lachman exam was found to be positive for 4 patients and negative for 87 patients. Pivot shift was positive for 4 patients and negative for 87 patients.

Table 2: Studies, Demographic Details, Surgical Technique, Time to Surgery, and Follow up.

\begin{tabular}{|c|c|c|c|c|c|c|c|c|}
\hline Reference & Study Design & Journal & Title & $\begin{array}{c}\text { Number of } \\
\text { patients }\end{array}$ & Mean Age & Technique & $\begin{array}{l}\text { Time to } \\
\text { Surgery } \\
\text { (months) }\end{array}$ & $\begin{array}{l}\text { Follow up } \\
\text { (months) }\end{array}$ \\
\hline Iorio, et al. & $\begin{array}{l}\text { Prospective } \\
\text { Cohort study }\end{array}$ & $\begin{array}{c}\text { Int Orthop } \\
2018\end{array}$ & $\begin{array}{c}\text { Anterior Cruciate } \\
\text { Ligament reconstruction } \\
\text { in patients older than fifty } \\
\text { years: a comparison with a } \\
\text { younger age group }\end{array}$ & 36 & $\begin{array}{c}54 \\
\text { Range } 50-62 \\
\text { SD } 3.69\end{array}$ & single bundle & NA & $\begin{array}{c}64 \\
\text { Range } 60-72\end{array}$ \\
\hline Kim, et al. & $\begin{array}{l}\text { Retrospective } \\
\text { Cohort Study }\end{array}$ & $\begin{array}{l}\text { Knee Surg } \\
\text { Sports } \\
\text { Traumatol } \\
\text { Arthrosc } \\
2019\end{array}$ & $\begin{array}{l}\text { Patients older than } 50 \\
\text { years had similar results } \\
\text { of knee strength and } \\
\text { anteroposterior stability } \\
\text { after ACL reconstruction } \\
\text { compared to younger } \\
\text { patients }\end{array}$ & 40 & $\begin{array}{l}52 \\
95 \% \text { CI } 51.0- \\
53.0\end{array}$ & single bundle & $\begin{array}{c}23.8 \\
95 \% \mathrm{CI} \\
16.5-30.1\end{array}$ & $\begin{array}{c}31.3 \\
95 \% \text { CI } 20.4- \\
45.2\end{array}$ \\
\hline $\begin{array}{c}\text { Kinugasa, } \\
\text { et al. }\end{array}$ & $\begin{array}{l}\text { Retrospective } \\
\text { Cohort Study }\end{array}$ & $\begin{array}{c}\text { Arthroscopy, } \\
2011\end{array}$ & $\begin{array}{l}\text { Effect of patient age on } \\
\text { morphology of anterior } \\
\text { cruciate ligament grafts at } \\
\text { second-look arthroscopy }\end{array}$ & 11 & $\begin{array}{c}58.5 \\
\text { Range } 50-71\end{array}$ & $\begin{array}{l}\text { double } \\
\text { bundle }\end{array}$ & $\begin{array}{c}27.4 \\
\text { Range } 1-158\end{array}$ & $\begin{array}{c}15.5 \\
\text { Range } 12-20\end{array}$ \\
\hline $\begin{array}{l}\text { Toanen, } \\
\text { et al. }\end{array}$ & $\begin{array}{l}\text { Retrospective } \\
\text { Case Series }\end{array}$ & $\begin{array}{l}\text { Am J Sports } \\
\text { Med, } 2017\end{array}$ & $\begin{array}{l}\text { Is there any benefit in } \\
\text { anterior cruciate ligament } \\
\text { reconstruction in patients } \\
\text { older than } 60 \text { years }\end{array}$ & 12 & $\begin{array}{c}61 \\
\text { SD } 1.4\end{array}$ & single bundle & $\begin{array}{c}11.5 \\
\text { Range 6-18 }\end{array}$ & $\begin{array}{c}49.6 \\
\text { SD } 24\end{array}$ \\
\hline $\begin{array}{l}\text { Trojani, } \\
\text { et al. }\end{array}$ & $\begin{array}{l}\text { Retrospective } \\
\text { Case Series }\end{array}$ & $\begin{array}{l}\text { Orthop } \\
\text { Traumatol } \\
\text { Surg Res, } \\
2009\end{array}$ & $\begin{array}{l}\text { Four-strand hamstring } \\
\text { tendon autograft for ACL } \\
\text { reconstruction in patients } \\
\text { aged } 50 \text { years or older }\end{array}$ & 18 & $\begin{array}{c}57 \\
\text { Range 51-66 }\end{array}$ & single bundle & $\begin{array}{c}11 \\
\text { Range 3-72 }\end{array}$ & $\begin{array}{c}31 \\
\text { Range 12-59 }\end{array}$ \\
\hline $\begin{array}{l}\text { Ventura, } \\
\text { et al. }\end{array}$ & $\begin{array}{c}\text { Retrospective } \\
\text { Case Series }\end{array}$ & $\begin{array}{c}\text { Arthroscopy, } \\
2012\end{array}$ & $\begin{array}{l}\text { Single and double-bundle } \\
\text { anterior cruciate ligament } \\
\text { reconstruction in patients } \\
\text { aged over } 50 \text { years }\end{array}$ & 50 & $\begin{array}{c}54.4 \\
\text { Range } 50-65\end{array}$ & $\begin{array}{l}\text { single bundle, } \\
\text { double } \\
\text { bundle }\end{array}$ & $\begin{array}{c}32.6 \\
\text { Range } 3-125\end{array}$ & $\begin{array}{c}41 \\
\text { Range } 24-84\end{array}$ \\
\hline
\end{tabular}

Table 3: Functional and Clinical Outcomes, NA indicates data not available.

\begin{tabular}{|c|c|c|c|c|c|c|c|c|}
\hline Reference & $\begin{array}{l}\text { Failure } \\
\text { Rate }\end{array}$ & Lachman & Pivot Shift & Satis-Faction & Lysholm (Preop) & $\begin{array}{l}\text { Lysholm } \\
\text { (Postop) }\end{array}$ & IKDC (Preop) & IKDC (Postop) \\
\hline Iorio, et al. & $0 \%$ & NA & NA & NA & $\begin{array}{c}53 \\
\text { SD } 2.45\end{array}$ & $\begin{array}{c}94.3 \\
\text { SD } 5.14\end{array}$ & $\begin{array}{c}54 \\
\text { SD } 5.32\end{array}$ & $\begin{array}{c}91.4 \\
\text { SD } 4.78\end{array}$ \\
\hline Kim, et al. & NA & NA & NA & NA & $\begin{array}{c}78.5 \\
95 \% \text { CI } 68.7-80.0\end{array}$ & $\begin{array}{c}93 \\
95 \% \text { CI 85-95 }\end{array}$ & $\begin{array}{c}61.2 \\
95 \% \text { CI } 51.8-68.8\end{array}$ & $\begin{array}{c}75.6 \\
95 \% \text { CI } 70.1-79.3\end{array}$ \\
\hline $\begin{array}{l}\text { Kinugasa, } \\
\text { et al. }\end{array}$ & $0 \%$ & $11 \mathrm{Neg}$ & $11 \mathrm{Neg}$ & NA & $\begin{array}{c}61 \\
\text { Range 52-74 }\end{array}$ & $\begin{array}{c}98 \\
\text { Range 93-100 }\end{array}$ & NA & NA \\
\hline $\begin{array}{l}\text { Toanen, } \\
\text { et al. }\end{array}$ & $0 \%$ & $\begin{array}{l}7 \text { Pos, } 5 \\
\text { Neg }\end{array}$ & 6 Pos, 6 Neg & $100 \%$ & $\begin{array}{c}55.7 \\
\text { SD } 12.4\end{array}$ & $\begin{array}{c}93.2 \\
\text { SD } 9.0\end{array}$ & $\begin{array}{c}43.4 \\
\text { SD } 8.4\end{array}$ & $\begin{array}{c}83.8 \\
\text { SD } 9.4\end{array}$ \\
\hline $\begin{array}{l}\text { Trojani, } \\
\text { et al. }\end{array}$ & $0 \%$ & $\begin{array}{l}3 \text { Pos, } 15 \\
\text { Neg }\end{array}$ & $\begin{array}{l}2 \text { Pos, } \\
16 \text { neg }\end{array}$ & $100 \%$ & NA & NA & NA & NA \\
\hline $\begin{array}{l}\text { Ventura, } \\
\text { et al. }\end{array}$ & $0 \%$ & $\begin{array}{c}1 \text { Pos, } 49 \\
\text { Neg }\end{array}$ & $\begin{array}{l}1 \text { Pos, } 49 \\
\text { Neg }\end{array}$ & NA & $\begin{array}{c}62 \\
\text { SD } 10.8\end{array}$ & $\begin{array}{c}90 \\
\text { SD } 6.4\end{array}$ & NA & NA \\
\hline
\end{tabular}




\section{Functional Outcomes}

The Lysholm score was reported in 5 studies with a total of 149 patients [8-16]. The mean pre-operative score ranged between 53 and 78.5. The mean post-operative score ranged between 90 and 98. Scores from 95-100 are considered excellent, 84-94 good, 65-83 fair, and less than 64 poor [17]. Meta-analysis of pre- and post-operative Lysholm score showed a pooled mean $(95 \% \mathrm{CI})$ difference of $32.90(26.05,39.75)$ using random-effects model (I2 $\left.=95 \%, \tau^{2}=52.89, \mathrm{p}<0.01\right)$. Meta-regression analysis showed that year of the study (coefficient: 0.08, SE: 3.88, p > 0.98) and, mean age of patients (coefficient: 0.82 , SE: $4.96, p>0.89$ ) were positively associated; and total number of patients in the study (coefficient: -0.28 , SE: $0.51, p>0.68$ ) was negatively associated with the mean difference in Lysholm score respectively, however, none of these associations were statistically significant. Egger's test and funnel plot do not indicate bias due to small-study effects (bias $=-4.85$, $\mathrm{SE}=3.46, \mathrm{p}>0.26$ ). The IKDC score was reported in 3 studies for a total of 88 patients [8-13]. The average pre-operative score was 55.8 (average min 43.4-max 61.2). The average post-operative score was 83.1 (average min 75.6-max 91.4). The Tegner activity score was reported in 3 studies for a total of 97 patients8,10,16. The average pre-injury score was 4.7 (average min 4-max 5.8). The average post-operative score was 5 (average min 3.7-max 5.4).

\section{Failure Rate and Complications}

Failure rate was reported to be $0 \%$ at final follow up in 5 studies [8-16]. There were no instances of patients reporting instability even in patients who had positive Lachman or pivot shift exams. Patient satisfaction was reported in 2 studies to be $100 \% 13,14$. The most common complication reported was saphenous nerve hypoesthesia, which was reported in one study in 3 of 18 patients 14 and in another study in 5 of 12 patients 13 while 3 studies reported no occurrences of nerve injury [8-16]. A single patient complained of posterior knee pain 14 while $17 \%$ in one study stopped sports participation for medical reasons unrelated to ACL reconstruction13.

\section{Discussion}

This systematic review provides significant insights into the clinical outcomes of patients over the age of 50 who have undergone ACL reconstruction using a hamstring autograft. Despite the heterogeneity of patient reported outcome tools utilized in the studies, good to excellent functional outcomes were achieved at final follow up in the majority of patients. Activity levels also increased in most patients as demonstrated by a slight increase in Tegner scores. No clinical failures or revisions were reported in this study. While the ideal graft choice for patients in this age group remains controversial, the results of this review would suggest that hamstring autograft can successfully be used in this cohort with good to excellent clinical outcomes.
Our results compare favorably to other similar studies. Gianluca Costa et al, recently published a systematic review examining the clinical and functional outcomes of ACL reconstructions in patients over 50 years of age 4 . They examined 470 patients with a variety of different autograft and allograft options and reported a comparable failure rate of $2.7 \%$. Also similar to our study, the authors reported a statistically significant improvement of clinical and functional outcome scores comparable to a younger control group. The authors concluded that age itself was not a contraindication to ACL surgery; however, no recommendations were made with respect to the optimal graft choice in this older population. While graft selection is often multifactorial, many authors have advocated for the use of hamstring autograft in older patients because of the wide availability, reduced donor site morbidity and fewer post-operative complications. This is supported by the results of our study as there were no reported graft re-tears requiring revision surgery and the most significant post-operative complication was a transient paresthesia in the saphenous nerve distribution that resolved in most patients. Patients also appeared to be highly satisfied with their graft choice and the patient satisfaction rate was reported to be $100 \%$ in both studies that included this metric $[13,14]$. Physical exam findings were reported in 87 patients and $95 \%$ were found to have a stable knee with a negative pivot shift and Lachman exams. Interestingly the 4 patients with a positive Lachman and pivot shift test, did not clinically feel unstable and did not require revision surgery. This finding is consistent with other similar studies [5-12] and is likely explained by the lower functional demands placed on the knee in this older cohort.

Another important finding in this study is that both functional outcome scores and overall activity level increased post-operatively as reflected by the improvement in Lysholm and Tegner scores, respectively. Lysholm, IKDC, and Tegner scores were all comparable to results seen in younger control groups and previous studies on ACLR for patients over 40 years of age which suggests that age alone should not be a cutoff for ACLR. A normative study by Anderson et al found that in a population 51-55 years of age, the mean IKDC score was 77 which suggests that post-operative ACLR patients have a higher score than their peers as our score was 83.2 [18]. In a validation study of the Lysholm score and Tegner activity scale by Briggs et al, the minimum detectable difference was found to be 8.9 for Lysholm and 1 for Tegner [19]. The results from our review indicate that the difference between pre-operative and post-operative Lysholm score $(\Delta-27.5)$ represent an increase while the Tegner scores $(\Delta 0.3)$ indicate that pre-injury and postoperative scores are statistically the same. A study by Wolfson et al suggests the only factor portending a negative outcome was found to be patellofemoral arthritis [20]. This finding suggests that while medial compartment or lateral compartment arthritis are often cited as reasons to avoid ACLR, this does not necessarily lead to worse outcomes. 
A number of limitations should be considered when interpreting the results of this systematic review. The overall level of evidence of the included studies was low and all studies were either prospective or retrospective case series, which in turn limits the strength of any conclusions drawn from this review. The majority of the studies lacked a control group of either non-operatively treated ACL tears or ACLRs performed using another graft option. The overall mean follow-up length was relatively short and while this may not have an impact on short term outcomes it may have influenced overall complication rates or number of patients progressing to arthroplasty. Another limitation is the heterogeneity in the outcome tools used to assess functional outcomes making pooling of the results difficult. Larger, prospective randomized clinical studies directly comparing various autograft and allograft options are needed to determine the optimal graft choice for ACLR in patients over 50 .

\section{Conclusion}

The results of this systematic review support hamstring autograft as a viable graft option for ACLR in patients over 50 with excellent functional outcomes, high patient satisfaction, low failure rates and minimal donor site morbidity.

\section{Conflict of Interest}

None of the authors have any conflicts of interest to disclose.

\section{References}

1. Mall NA, Chalmers PN, Moric M, Tanaka MJ, Cole BJ, et al. (2014) Incidence and trends of anterior cruciate ligament reconstruction in the United States. Am J Sports Med 42(10): 2363-2370.

2. Ciccotti MG, Lombardo SJ, Nonweiler B, Pink M (1994) Non-operative treatment of ruptures of the anterior cruciate ligament in middle-aged patients. J Bone Jt Surg Am 76: 1315-1321.

3. Baker CL Jr, Jones JC, Zhang J (2014) Long-term outcomes after anterior cruciate ligament reconstruction in patients 60 years and older. Orthop J Sports Med 2(12): 2325967114561737.

4. Costa GG, Grassi A, Perelli S, Agro G, Bozzi F, et al. (2019) Age over 50 years is not a contraindication for anterior cruciate ligament reconstruction. Arthroscopy 27: 3679-3691.

5. Cinque ME, Chahla J, Moatshe G, Phillipo NN, Kennedy NI, et al. (2017) Outcomes and complication rates after primary anterior cruciate ligament reconstruction are similar in younger and older patients. Orthop J Sports Med 5(10): 2325967117729659.
6. Dahm DL, Wulf CA, Dajani KA, Dobbs RE, Levy BA, et al. (2008) Reconstruction of the anterior cruciate ligament in patients over 50 years. J Bone Jt Surg Br 90: 1446-1450.

7. Figueroa D, Figueroa F, Calvo R, Vaisman A, Espinoza G, et al. (2014) Anterior cruciate ligament reconstruction in patients over 50 years of age. Knee 6(21): 1166-1168.

8. Iorio R, Iannotti F, Ponzo A, Proietti L, Redler A, et al. (2018) Anterior cruciate ligament reconstruction in patients older than fifty years: a comparison with a younger age group. International Orthopedics 42: 1043-1049.

9. Kim DK, Park G, Kuo LT, Park WH (2019) Patients older than 50 years had similar results of knee strength and anteroposterior stability after ACL reconstruction compared to younger patients. Knee Surg Sports Traumatol Arthrosc 27(1): 230-238.

10. Kinugasa K, Mae T, Matsumoto N, Nakagawa S, Yoneda M, et al. (2011) Effect of patient age on morphology of anterior cruciate ligament grafts at second-look arthroscopy. Arthroscopy 27: 38-45.

11. Miller MD, Sullivan RT (2001) Anterior Cruciate Ligament Reconstruction in an 84- year old man. Arthroscopy 17(1): 70-72.

12. Nishio Y, Kondo E, Onodera J, Onodera T, Yagi T, et al. (2018) Doublebundle anterior cruciate ligament reconstruction using hamstring tendon hybrid grafts in patients over 40 years of age. Orthop J Sports Med 6(5): 2325967118773685

13. Toanen C, Demey G, Ntagiopoulous PG, Ferrua P, Dejour D (2017) Is there any benefit in anterior cruciate ligament reconstruction in patients older than 60 years? Am J Sports Med 45(4): 832-837.

14. Trojani C, Sane JC, Coste JS, Boileau P (2009) Four-strand hamstring tendon autograft for ACL reconstruction in patients aged 50 years or older. Orthop Traumatol Surg Res 95(1): 22-27.

15. Vaishya R, Dhiman RS, Vaish A (2014) Anterior cruciate ligament reconstruction in a 75 years old man: a case report with review of literature. Chin J Traumatol 17(2): 121-124.

16. Ventura A, Legnani C, Terzaghi C, Borgo E (2012) Single- and doublebundle anterior cruciate ligament reconstruction in patients aged over 50 years. Arthroscopy. 28(11): 1702-1709.

17. Collins NJ, Misra D, Felson DT, Crossley KM, Roos EM (2011) Measures of Knee Function. Arthritis Care Res 63 (0 11): S208-S228.

18. Anderson A, Irrgang J, Kocher M, Mann B, Harrast J (2005) International Knee Documentation Committee (2006) The International Knee Documentation Committee Subjective Knee Evaluation Form: Normative Data. Am J Sport Med 34(1): 128-135.

19. Briggs K, Lysholm J, Tegner Y (2009) The Reliability, Validity, and Responsiveness of the Lysholm Score and Tegner Activity Scale for Anterior Cruciate Ligament Injuries of the Knee: 25 years Later. Am J Sports Med 37(5): 890-897.

20. Wolfson T, Epstein D, Day M, Joshi B, McGee A, et al. (2013) Outcomes of anterior cruciate ligament reconstruction in patients older than 50 years of age. Bull Hosp Jt Dis 72(4): 277-283. 
(c) (i) This work is licensed under Creative

To Submit Your Article Click Here:

Submit Article

DOI: $10.32474 /$ OSMOAJ.2020.04.000193

$\begin{gathered}\text { Orthopedics and Sports Medicine } \\ \text { Open Access Journal }\end{gathered}$
Assets of Publishing with us
- Global archiving of articles
- Immediate, unrestricted online access
- Rigorous Peer Review Process
- Authors Retain Copyrights
Orthopedics And Sports Medicine:
Open Access Journal

